\title{
HIV and STI Testing Preferences for Men Who Have Sex with Men in High-Income Countries: A Scoping Review
}

\author{
Varsicka Kularadhan ${ }^{1, *,+}{ }^{+}$, Joscelyn Gan ${ }^{2,+}$, Eric P. F. Chow ${ }^{3,4,5} \mathbb{D}$, Christopher K. Fairley ${ }^{3,4}$ \\ and Jason J. Ong ${ }^{3,4,5,6}$ iD
}

Citation: Kularadhan, V.; Gan, J.; Chow, E.P.F.; Fairley, C.K.; Ong, J.J. HIV and STI Testing Preferences for Men Who Have Sex with Men in High-Income Countries: A Scoping Review. Int. J. Environ. Res. Public Health 2022, 19, 3002. https:// doi.org/10.3390/ijerph19053002

Academic Editor: Paul B. Tchounwou

Received: 8 January 2022

Accepted: 24 February 2022

Published: 4 March 2022

Publisher's Note: MDPI stays neutral with regard to jurisdictional claims in published maps and institutional affiliations.

Copyright: (C) 2022 by the authors. Licensee MDPI, Basel, Switzerland. This article is an open access article distributed under the terms and conditions of the Creative Commons Attribution (CC BY) license (https:// creativecommons.org/licenses/by/ $4.0 /)$.
1 School of Rural Health, Monash University, Bendigo, VIC 3550, Australia

2 Melbourne Medical School, The University of Melbourne, Parkville, VIC 3010, Australia; joscelyng@student.unimelb.edu.au

3 Central Clinical School, Monash University, Melbourne, VIC 3800, Australia; echow@mshc.org.au (E.P.F.C.); cfairley@mshc.org.au (C.K.F.); jason.ong@monash.edu (J.J.O.)

4 Melbourne Sexual Health Centre, Alfred Health, Carlton, VIC 3053, Australia

5 Melbourne School of Population and Global Health, The University of Melbourne, Parkville, VIC 3010, Australia

6 Department of Clinical Research, London School of Hygiene and Tropical Medicine, London WC1E 7HT, UK

* Correspondence: varshkularadhan@bendigohealth.org.au

+ These authors contributed equally to this work.
Abstract: Background: Regular testing for HIV and other sexually transmitted infections (STI) is recommended at least annually for sexually active men who have sex with men (MSM) in most high-income countries. To encourage regular use of HIV and STI testing and treatment services for MSM, we reviewed the literature to summarise the attributes of an HIV/STI testing service that MSM prefer. Method: We conducted a scoping review, searching PubMed, EMBASE, PsycINFO and CINAHL in January 2020 for articles reporting primary data on the preferences of MSM (living in high-income countries) for HIV/STI testing services. Two reviewers independently screened titles and abstracts and any discrepancies were resolved by a third reviewer. We extracted data on the service attributes that MSM preferred and summarised these thematically using a socioecological framework. Results: In total, 1464 publications were identified, 220 full texts were read and 57 were included in the final analysis. We found 21 articles addressing 'individual' attributes, 50 articles addressing 'service' attributes and 17 articles addressing 'societal' attributes. The key themes of preferences for HIV/STI testing services were: (1) the appeal of self-testing due to convenience and privacy; (2) the need to provide a variety of testing options; and (3) the influence of the testing experience, including confidentiality and privacy, tester characteristics and stigma. There were distinct patterns of preferences for subpopulations of MSM across studies, such as the preference of self-testing for young MSM, and of in-clinic testing for those who perceived themselves as high risk (i.e., with symptoms of STIs or exposed to a partner living with HIV). Conclusion: To make HIV/STI testing more accessible for MSM and encourage regular screening, it is important to address 'individual', 'service' and 'societal' attributes, such as enhancing the convenience of testing through self-testing, and providing a service that men feel comfortable and safe accessing. Furthermore, services should accommodate the preferences of diverse sub-populations within the MSM community.

Keywords: HIV; sexually transmitted infection; health service delivery; men who have sex with men

\section{Introduction}

Worldwide, there was estimated to be 1.7 million new HIV infections in 2019, and although this has declined significantly over the last ten years, numerous countries are not on track to meet 2020 and 2030 global targets for reductions in HIV incidence and mortality [1,2]. Men who have sex with men (MSM) continue to be disproportionately affected by 
HIV and sexually transmitted infections (STIs), even in high-income countries [3]. Globally, MSM are 26 times more at risk of acquiring HIV compared to heterosexual men [4].

As early HIV and most STIs can be asymptomatic, timely access to testing and treatment is critical for controlling HIV/STIs [5]. Although screening frequency varies across countries, the current overall screening frequency is not enough to control the rising epidemics of STIs. Rates of STIs in various high-income countries, including the US, across Europe and Australia, continue to rise within the MSM population, with the incidence greater than that of women and men who have sex with women only [6-8]. HIV/STI testing amongst this population has been reported to be suboptimal. A US cross-sectional study found that one-third of the sample had not been tested in the previous two years. In Australia, low frequency of testing and incomplete testing (i.e., chlamydia and gonorrhoea testing at three body sites and syphilis testing alongside all HIV testing) in MSM have been identified as one of the main barriers to HIV/STI control $[9,10]$. In other high-income countries, such as the US and Western Europe, limited access to HIV testing and care, and financial barriers act as significant barriers for regular testing among MSM [1].

HIV/STI testing can be delivered in a variety of ways including via hospitals, general practice, community-based organisations and home testing. Over the last five years, there have been a growing body of studies reporting the various attributes of HIV /STI testing services that MSM prefer. To date, systematic reviews have only focused on preferences related to HIV self-testing, but there has not been a review that synthesises the attributes of testing services that MSM prefer [11,12]. We reviewed the literature to provide an overview of the attributes of an HIV/STI testing service that MSM prefer, and to identify barriers to access. This review may be utilised to adapt current services or create new services that account for these preferred attributes, in order to improve the uptake of HIV/STI screening among MSM and decrease the prevalence of HIV/STIs.

\section{Materials and Methods}

\subsection{The Search Strategy and Inclusion Criteria}

We conducted a systemic review (Prospero: CRD42020179720) of the existing literature on the attributes of HIV /STI testing services preferred by MSM in high-income countries. We aimed to answer the following review question "In MSM living in high-income countries, which attributes of HIV /STI testing services do they prefer and not prefer?" To allow comparability between articles, we did not include publications from low- and middleincome countries as there are significant differences in their health systems compared to high-income countries. A literature search was conducted in January 2020 and updated in February 2022 using four electronic databases: MEDLINE (via PubMed), EMBASE, PsycINFO and CINAHL. Additional literature was included from hand searches in the reference lists of included articles. The search terms included across all databases related to (1) sexually transmitted infections, (2) health services and (3) testing or patient preferences. The search terms were: ("sexually transmitted infection" OR "sexually transmitted disease" OR "STI" OR "STD") AND ("health service" OR "sexual health service") AND ("testing" OR "preference" OR "patient preference" OR "perspective" OR "acceptability" OR "experience" OR "satisfaction"). No search filters were used. The full search strategy is provided in Tables S1-S4. The initial search was screened independently for relevant articles based on titles and abstracts meeting the inclusion criteria by two authors (JG, VK). Any discrepancies were resolved by a third author (JO).

To be included, studies were required to report primary data on the preferences for attributes of HIV/STI testing services among MSM living in high-income countries (as per the World Bank definition). Articles that were not written in English, were conducted in lowor middle-income countries or were dated before 2000 were excluded. All citations were imported onto the citations manager, EndNote X9, and duplicates were removed initially by the citation manager. Duplications found later on in the process were manually deleted. 


\subsection{Data Analysis}

Data on testing preferences of MSM were extracted independently by two authors (JG, VK) using standardised extraction forms. We extracted data related to the setting of the study, the attributes tested, whether attributes were preferred or not preferred, and the characteristics of the study population. Data from the extraction forms were coded thematically into predefined themes using a socioecological framework, a commonly used model in public health interventions to understand the influences of individual-, serviceand societal-level factors [13]. Two reviewers (VK, JG) independently coded the data, with a third reviewer (JO) resolving any discrepancies. Key attributes were then identified from the coded data and expanded upon further. Our findings are reported according to the PRISMA (Preferred Reporting Items for Systematic review and Meta-Analysis) checklist (Table S5).

\section{Results}

The initial search resulted in 1834 potentially relevant articles. An updated search resulted in 330 potentially relevant articles. After screening, 84 articles were included (Figure 1).
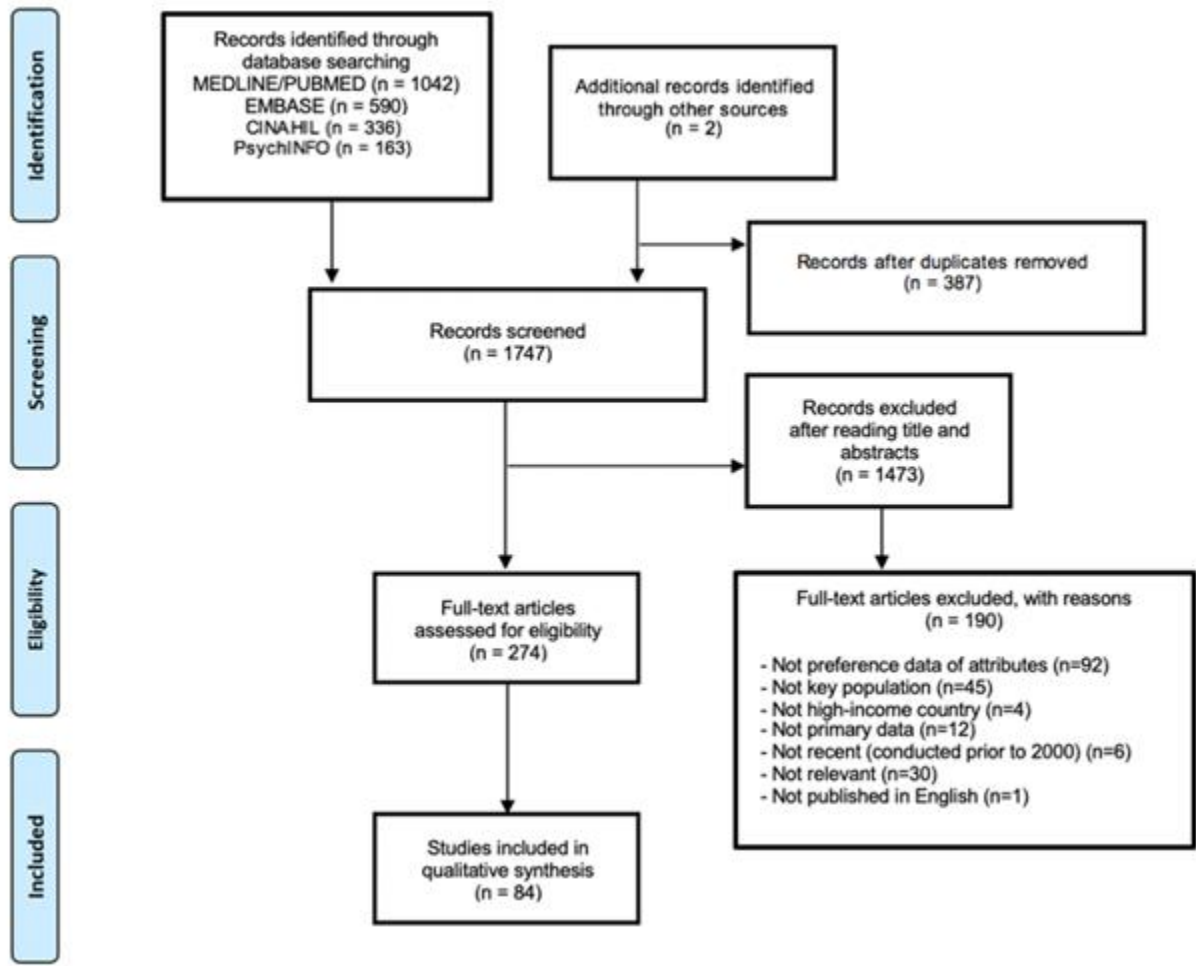

Figure 1. PRISMA flow diagram.

\subsection{Study Characteristics}

The majority of studies were conducted in the United States (US, $n=35$ ), the United Kingdom (UK, $n=16)$, Australia $(n=14)$ and Europe $(n=11)$. A small number of studies were conducted in Canada $(n=6)$ and Asia $(n=2)$. Of 84 studies, 33 utilised interviews and focus groups, 30 utilised quantitative surveys, 9 were mixed methods, 7 were randomised controlled trials, 3 used data from records of pre-existing clinical services and 2 were discrete-choice experiments (Table S6). Forty-six were based on HIV testing, twenty on STI testing and eighteen on both HIV and STI testing. Eight studies focused on young MSM, five of which were specifically young African American MSM. Eight studies focused on MSM of colour. There were few data on first-time testers $(n=2)$ and MSM with high-risk profiles $(n=4)$. 


\subsection{Socioecological Framework}

Included articles were categorised using a socioecological framework: 30 articles addressed 'individual' attributes, 65 articles addressed 'service' attributes and 18 articles addressed 'societal' attributes. Figure 2 presents an overview of the attributes identified, and Tables S1-S3 categorise each study according to evidence of whether the attribute increases or decreases uptake of HIV/STI testing services.

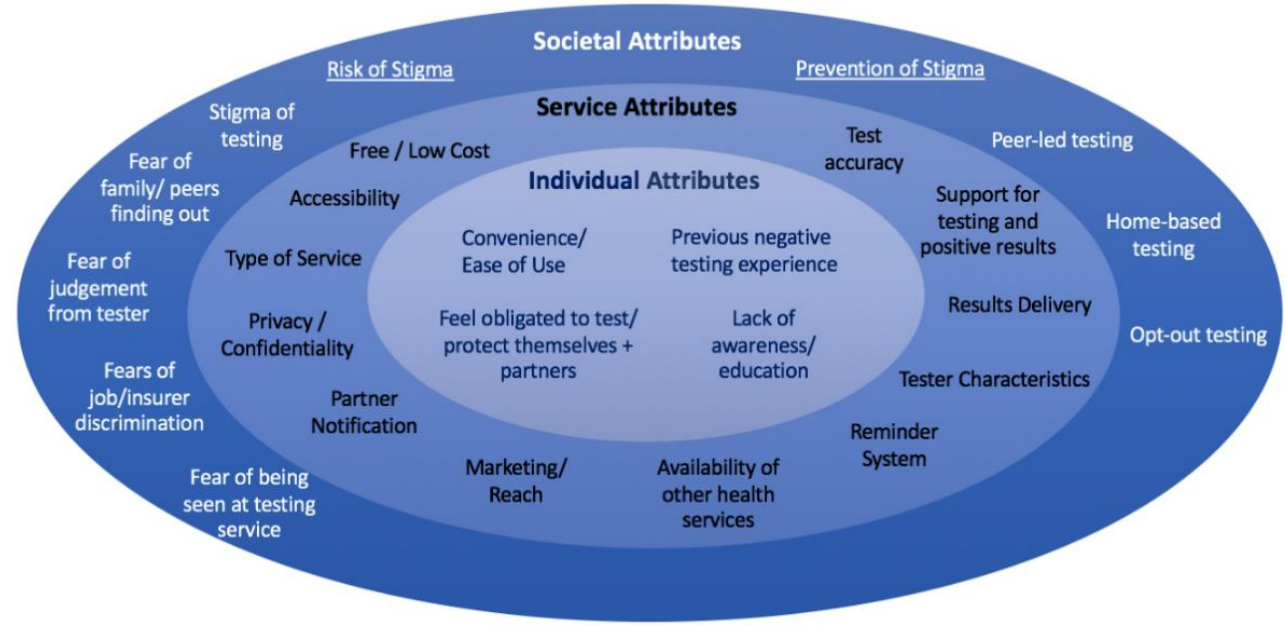

Figure 2. Summary of attributes using the socioecological framework.

\subsection{Individual Attributes}

\subsubsection{Convenience}

Convenience was a key attribute for MSM who preferred home self-sampling [14,15] or self-testing [16-27] (Table 1). A study conducted in the UK used focus groups and interviews with 44 MSM to explore the acceptability of home self-sampling kits [14]. The kits were highly acceptable, as men could perform the test at any time without needing to book an appointment and waiting times were important factors. It was also noted that these kits increased access to testing for participants who were geographically isolated or unable to access clinics due to work shift patterns [14]. Two studies conducted in the UK highlighted a preference for postal delivery of self-testing and self-sampling kits to increase convenience $[15,20]$. However, participants in one of these studies based on semi-structured interviews with 24 MSM about self-sampling raised concerns about the unreliability of postal services and the possibility of damage to specimens in transit [15]. This study also found that clinic attendance was preferred if participants were symptomatic, had been exposed to an infection, or a sexual partner had tested positive [15]. The other study, which conducted focus groups with 47 MSM about self-testing, found it was essential to offer a range of access options to maintain convenience and privacy [20].

Despite the appeal of the convenience of self-testing, we found three studies that identified issues with self-testing [28-30]. One study, conducted in the US, used a series of focus-group discussions with 21 young MSM of colour (aged 18-35 years) to explore the acceptability, preferences and usability of HIV self-test kits [29]. Identified issues included the instructions being too complicated and not user-friendly, privacy concerns with purchasing the kit and that the packaging itself was too bulky, clinical and outdated [29]. Another study, conducted in the UK, used semi-structured interviews to understand the acceptability of HIV self-testing (HIVST) amongst 37 MSM [30]. It identified difficulties with using the lancet; however, participants felt that this was only an issue during first-time use. Participants receiving repeat HIVST kits confirmed that repeated use increased confidence and competence [30]. Both studies discussed concerns about the user's capacity to perform the test, as well as concerns about the accuracy and reliability of the test $[29,30]$. 
Table 1. Identified attributes of STI testing services—individual attributes.

\begin{tabular}{|c|c|}
\hline Attribute & Attribute Examples \\
\hline \multirow[t]{3}{*}{ Convenience/Ease of Use of Testing } & Self-testing $(+)$ [16-27] \\
\hline & Self-testing $(-)[28-30]$ \\
\hline & Self-sampling $(+)[14,15,21]$ \\
\hline \multirow[t]{7}{*}{ Barriers } & Previous negative experience $(-)[28,31-35]$ \\
\hline & Lack of awareness/education $(-)[14,36,37]$ \\
\hline & Confidentiality concerns in community-based settings $(-)$ [38] \\
\hline & Perceived low risk $(-)[36,39]$ \\
\hline & Lack of priority/lifestyle too busy $(-)[33,39]$ \\
\hline & Fear of positive result $(-)[34]$ \\
\hline & Medical mistrust (-) [35] \\
\hline \multirow[t]{3}{*}{ Individual Attitudes/Perceptions } & Lack of testing among peers $(-)[40]$ \\
\hline & $\begin{array}{l}\text { Feel obligated to test/protect themselves }+ \text { partners }(+) \\
\qquad[14,15,19,22,26,40,41]\end{array}$ \\
\hline & $\begin{array}{c}\text { Testing in response to risk incidents, unexpected symptoms or part } \\
\text { of a sexual health routine }(+)[42]\end{array}$ \\
\hline
\end{tabular}

\subsubsection{Previous Testing Experience}

Six studies suggested a previous negative experience of the testing process to be an important barrier to HIV/STI testing [28,31-35]. Common themes which emerged included feeling embarrassed during previous testing experiences and discomfort about discussing their sexual history. A study using 30 semi-structured interviews with young African American MSM and transgender women in New York City (NYC) found that many had past experiences of testing filled with anxiety, which deterred them from future testing. In particular, negative relationships with and perceived negative attitudes of testers towards participants were important aspects of past testing [34]. Additionally, another study found that, even with positive past testing experiences, some men preferred not to go back to the location they first received their HIV diagnosis due to a now-negative association with the clinic [40]. This study, conducted in Amsterdam, used semi-structured qualitative interviews with $30 \mathrm{HIV}$-positive MSM to look at their sexual health practices in the year following their HIV diagnosis [40].

\subsubsection{Attitudes and Perceptions}

Six studies identified that a feeling of obligation to protect themselves and their partners was an important reason for testing amongst MSM [14,15,19,22,39,40]. This finding was consistent across a variety of settings. A study from the US surveyed 460 participants at a needle exchange, three sex venues for MSM and an STI clinic [19]. Of the data from the sex venues in which the majority were MSM $(87 \%, n=139)$, most participants $(84.4 \%)$ reported that not wanting to infect others was a strong motivator for HIV testing. Concern about exposure $(78.9 \%)$ and wanting early treatment $(78.2 \%)$ were also found to be significant motivators [19]. Another study which interviewed HIV-positive MSM in Amsterdam found that important motivators for regular STI testing were looking after their sexual health, protecting their partners and feeling more vulnerable to STIs (than before their diagnosis) [40].

A study which surveyed MSM with low intentions of actively seeking HIV testing in Spain found that those a majority of these men (49\%) did not seek testing due to believing they were at low risk of contracting HIV compared to those who had high testing intentions [39]. 


\subsection{Service Attributes}

\subsubsection{Type of Service}

Thirty-three studies identified home-based self-testing or self-sampling as the preferred method of testing [14-20,22-24,26,29,31,43-61] (Table 2). Three randomised controlled trials (RCT) found that HIVST increased testing frequency, and therefore was preferred by MSM compared to usual testing [17,21,54]. A US trial randomised 230 high-risk HIV-negative MSM to access oral fluid HIV self-tests at no cost versus testing as usual for 15 months [17]. There was an average use of 3.9 self-tests per person in the free self-testing group over the 15-month period, which was an increase of 1.7 tests per person compared to the testing as usual group [17]. Another US RCT randomised 65 HIV-negative MSM into three groups: HIVST kits by mail with a follow-up call from a counsellor (eTEST), standard HIVST kits with no follow-up (standard), or letters containing information about HIV testing locations (control) [53]. Delivery of HIVST kits by post at 3-month intervals increased testing, with all participants from the eTEST and standard groups testing at least once during the 7-month period compared to $72 \%$ of the control group. There was also nearly double the rate of repeat testing amongst these intervention groups [53]. The last RCT, conducted in Australia, randomised 362 men to free HIV self-testing plus facility-based testing, or facility-based testing only. Compared to standard care, self-testing doubled the frequency of testing in MSM and increased testing by nearly four times in non-recent testers [21].

Table 2. Identified attributes of STI testing services-Service Attributes.

\begin{tabular}{|c|c|}
\hline Attribute & Attribute Examples \\
\hline \multirow[t]{8}{*}{ Type of Service } & Self-testing/Self-sampling (+) [14-20,22-24,26,29,31,43-61] \\
\hline & Self-collection $(+)[21,31]$ \\
\hline & Self-collection $(-)[18,21]$ \\
\hline & Mobile testing (+) [62] \\
\hline & Mobile testing (-) [32] \\
\hline & Online testing service $(+)[43]$ \\
\hline & Rapid testing (+) $[18,19,30,31,34,36,45,49,51,63,64]$ \\
\hline & Express service $(+)[65]$ \\
\hline \multirow[t]{6}{*}{ Accessibility } & Appointment system availability (-) [28] \\
\hline & Appointment system ease of use (+) [66] \\
\hline & Walk-in Service (+) [62] \\
\hline & Waiting times $(-)[66]$ \\
\hline & Self-testing kits available at a variety of locations $(+)[22,54,59]$ \\
\hline & Non-specialist setting $(-)[67]$ \\
\hline \multirow[t]{6}{*}{ Type of Test } & Oral (+) [16] \\
\hline & Rectal (+) [68] \\
\hline & Urine $(+)[28]$ \\
\hline & Blood (+) $[25,34]$ \\
\hline & Venepuncture (-) [19] \\
\hline & Other attributes (e.g., cost, speed) $>$ type of test $(+)[16,27]$ \\
\hline \multirow[t]{3}{*}{ Accuracy } & High accuracy $(+)[26,34]$ \\
\hline & Accuracy > convenience of sample collection $(+)[14]$ \\
\hline & $\begin{array}{c}\text { Concerns about accuracy/reliability of self-testing and rapid } \\
\text { testing }(-)[22,28]\end{array}$ \\
\hline \multirow[t]{3}{*}{ Cost } & Free/low cost $(+)[17,18,27,49,54,55,69,70]$ \\
\hline & No health insurance $(-)[28]$ \\
\hline & Cost $(-)[27,37,59]$ \\
\hline
\end{tabular}


Table 2. Cont.

\begin{tabular}{|c|c|}
\hline Attribute & Attribute Examples \\
\hline \multirow[t]{7}{*}{ Privacy, Confidentiality \& Anonymity } & $\begin{array}{c}\text { Fears of disclosing sexual identity or behaviour in an unfamiliar } \\
\text { environment }(-)[48]\end{array}$ \\
\hline & Privacy/anonymity when testing + receiving results $(+)[28]$ \\
\hline & Open waiting room $(-)[14]$ \\
\hline & Non-specialist setting $(-)$ [32] \\
\hline & Picking up of self-testing kit from pharmacy/clinic (-) [29] \\
\hline & Named reporting $(-)[19]$ \\
\hline & Providing personal information online $(-)$ [71] \\
\hline \multirow[t]{8}{*}{ Tester Characteristics } & Credibility of tester and legitimacy $(+)[18,28,32,35,48]$ \\
\hline & Tester attitude $(+)[28,32,33,42,71-73]$ \\
\hline & Risk of being recognised (-) [64] \\
\hline & $\begin{array}{l}\text { Familiarity with tester/comfortable environment }(+) \\
\qquad[18,27-29,64]\end{array}$ \\
\hline & Skill/knowledge of tester $(+)[18,32,34,37,71,72]$ \\
\hline & Healthcare professional (+) [28] \\
\hline & Peer-testing $(+)[51]$ \\
\hline & Lack of trans knowledge $(-)$ [35] \\
\hline \multirow[t]{5}{*}{ Results Delivery } & In person/via phone call if positive (+) $[15,19,20,31,71,73,74]$ \\
\hline & Online results/via phone app $(+)[27,43,58,73]$ \\
\hline & Online results $(-)[59,75]$ \\
\hline & Quick/immediate results $(+)[27,59]$ \\
\hline & Through text if negative $(+)[31]$ \\
\hline \multirow[t]{9}{*}{ Support for Testing and Positive Results } & Education/counselling $(+)[18,36,48,59,71,76-78]$ \\
\hline & Availability of immediate treatment $(+)[27,28]$ \\
\hline & Face to face counselling (-) [19] \\
\hline & Linkage to care $(+)[79]$ \\
\hline & Linkage of results to other health professionals $(+)[18,27,73]$ \\
\hline & Home-based testing: support offered $(+)[45]$ \\
\hline & Partner delivered partner therapy $(+)[55]$ \\
\hline & Anonymous partner notification $(+)[55]$ \\
\hline & Self-testing: lack of support (-) $[14,20,24,38,49,59,75]$ \\
\hline \multirow[t]{3}{*}{ Reminder System } & From local health department $(+)$ [28] \\
\hline & From online service $(+)[50]$ \\
\hline & From STI testing service $(+)[36]$ \\
\hline \multirow[t]{2}{*}{ Partner Notification } & Via phone app (+) $[43,80]$ \\
\hline & Anonymous e-card $(+)[70]$ \\
\hline \multirow[t]{5}{*}{ Availability of Other Health Services } & Offering other health services $(+)$ [36] \\
\hline & Self-testing: lack of availability of other health services (-) [49] \\
\hline & Lack of co-testing of other STIs (-) [64] \\
\hline & $\begin{array}{l}\text { Integrating testing with ongoing monitoring for hormone } \\
\text { therapy }(+)[35]\end{array}$ \\
\hline & Availability of condoms and lubricants (+) [36] \\
\hline Reach/Marketing & Use of apps/internet (+) [70] \\
\hline
\end{tabular}

$(+)$ study reported this as a preferred attribute; $(-)$ study reported this as a non-preferred attribute. 
Confidentiality or privacy was identified to be a common reason for preferring selftesting amongst MSM $[14,25,27,34,49,51,52,60]$. One study, conducted in the Netherlands, used semi-structured interviews to explore key factors which allowed for the successful implementation of social network testing with HIV self-tests [48]. It found that MSM valued not having to discuss their sexual identity or disclose sexual behaviours and avoided being seen at a testing facility [48]. Another study, which conducted 30 in-depth interviews with young MSM and transgender women in NYC, found similar themes; however, it also noted that living with parents may act as a barrier to self-testing, as they would like to avoid uncomfortable questions or conversations regarding testing [34].

A cross-sectional survey that recruited 15,704 MSM in England found that although genitourinary medicine (GUM) clinics were most popular amongst MSM, self-testing was preferred amongst first-time testers [52]. It also identified that this population valued the availability of a variety of testing methods and settings [52]. Another study that used semistructured interviews with 24 MSM in the UK to explore their opinions on self-sampling kits identified that although the convenience of these kits was appreciated, testing at a clinic was preferred if they were symptomatic, exposed to an infection, or a sexual partner had tested positive [15].

One study conducted focus groups with 36 young African American MSM in Alabama, US, found overall negative opinions about self-testing at home due to concerns about accuracy and preferred to be tested by trusted physicians [28].

Another US study, which assessed data from a pilot RCT looking at STI self-collection, found that whilst self-testing gave MSM more control over their sexual health, there were some frustrations with tests which required blood-sample collection [21].

\subsubsection{Type of Testing}

A study conducted in California, US, which used the surveys of 354 MSM clients of public testing services, identified the method of testing to be the least important attribute of HIV testing [18]. It found that accuracy, timeliness, the privacy of test disclosure, and linking of test results were equally ranked as the most important attributes. The availability of in-person counselling was ranked next and was also identified to be the strongest predictor of 'loyalty' to public clinic tests (even if other options were offered for free) [18]. Overall, there were widespread preferences for the type of testing (e.g., oral, blood, urine, rectal). A study conducted in NYC examined the computer-assisted self-interviews of 83 MSM to determine their preference of oral swab vs. blood-based HIV rapid testing [16]. It found that the majority preferred oral swabs, but they were more likely to consider the bloodbased testing if it was cheaper, gave faster results and included co-testing of other STIs [16]. Similar results were also noted among a rural cohort of MSM in the US, which found if two HIV self-tests were available over the counter and cost the same, MSM were more likely to use the gym swab over the fingerpick blood test. However, if the cost of the fingerpick self-test cost half the price, and tested for other STIs, the preference for the fingerpick self-test increased [27]. Three studies discussed that the perceived greater accuracy of testing a blood sample compared to other samples was an important consideration in their preferences $[20,28,34]$. One study addressed the importance of wanting control over specimen collection, i.e., collecting their own specimen [50]. This study, conducted in Canada, used in-depth semi-structured interviews to explore the experiences of MSM who used an internet-based HIV and STI testing service, GetCheckedOnline.com [50].

\subsubsection{Rapid Testing}

Eleven studies identified a preference for rapid testing $[18,19,30,31,34,36,45,49,51,63,64]$. Two studies, both conducted in Australia, highlighted that clients would test more frequently if rapid testing was available (rapid testing was not available in Australia at the time these studies were conducted) [51,63]. One of these studies, which used acceptability questionnaires to explore the HIV testing preferences of 1061 MSM, found that they preferred rapid testing as it was more convenient, more comfortable and less stressful than conventional HIV testing [63]. The 
other study, which used anonymous questionnaires to explore the syphilis testing preferences of 183 MSM, identified that $79 \%$ preferred rapid tests if they were available at clinics, and $70 \%$ of participants would test more frequently if this was the case [51]. The most common reasons for this were immediate results, reduced pain/invasiveness compared to venepuncture, and the convenience of not requiring a second appointment for results [51]. Another study, which used surveys with 460 MSM to identify motivators, barriers and preferences for HIV testing, found a preference for rapid testing, both in the clinic (27\%) and at home (20\%) [19]. Rapid testing was preferred due to faster results and less anxiety, with home-based rapid testing in particular allowing for more privacy and convenience. Only 31\% of participants raised concerns about home-self testing; the majority were unsure about the accuracy of these tests, and some were concerned about user error and lack of counselling [19].

\subsubsection{Cost}

Eight studies identified that free/low-cost testing was an important consideration for MSM [17,18,26,42,50,55,56,71]. A mixed-method study exploring the acceptability of self-testing in the UK used data collected from self-completed questionnaires and oral fluid specimen collections of 999 MSM and conducted 12 expert focus groups with MSM, health professionals, community organisations, entrepreneurs and activists [49]. It found that cost was an important consideration when using self-testing kits, with $80 \%$ of participants being likely to use self-tests if they were provided for free, compared to only $45.2 \%$ of MSM willing to pay for the tests [49]. An RCT conducted in Washington, US, randomly assigned 230 MSM to access free oral fluid HIV self-tests versus testing as usual [17]. Of these MSM, $15 \%$ would pay USD 40 or more for a self-test, $27 \%$ would pay USD $20-40,33 \%$ would pay USD 10-20,13\% would pay less than USD 10, and 12\% would only use a self-test if it were free. MSM also reported that the frequency of self-testing would be dependent on cost, with $87 \%$ saying they would test four or more times per year if it cost USD 5 compared to only $23 \%$ if it cost USD 50 [17]. Similarly, another US study found three-quarters of participants were willing to spend up to USD 20 for a HIV self-testing kit. However, many would rather utilise free community testing over paying for a HIV self-testing kit [26].

An online discrete choice experiment conducted in the UK with 620 MSM found that the majority had a preference for face-to-face testing with a healthcare professional compared to remote testing [68]. However, when the choice was between free remote testing or paying GBP 30 ( USD 40), there was a shift to remote testing [69]. Another study, which surveyed MSM clients of public testing services in California, US, found that if all tests were offered at no cost, although a public clinic test remained most preferred, self-tests became more popular [18].

A study that conducted focus groups with 36 young African American MSM in Alabama, US, found that privacy and confidentiality were important when seeking STI testing [28]. Participants highlighted that a private doctor's office was ideal for these reasons, as there was no assumption of being there for STI testing, and medical professionals were obligated to maintain confidentiality. However, they also noted that this is not an option for many individuals as it requires private health insurance or the ability to pay out-of-pocket. Participants agreed that although STI testing at the local health department had a major drawback in terms of privacy and confidentiality, the low/no cost of testing and the availability of immediate treatment was considered more important [28].

\subsubsection{Tester Characteristics}

Tester characteristics was an important consideration, particularly tester credibility/ legitimacy [18,28,32,35,49], attitude [28,32,33,42,71,72], skill/knowledge [18,32,34,37,71,72] and familiarity with tester $[18,28,29,36]$. Gender of tester was not identified as an important consideration in any studies.

A study of eight focus group discussions with 61 MSM in the UK explored their views and experiences of accessing sexual health services [32]. It identified that testers being professional, knowledgeable and non-judgemental was very important to this population. 
Participants noted that the staff's demeanour and behaviour mades a significant difference in their testing experience, and they were also highly sensitive to how they felt the staff perceived them. They also noted that they would like staff to be well-informed about the latest research and practice evidence-based medicine. Some participants preferred services which specialised in working with MSM, stating that they felt more understood; however, this was not a collective preference [32]. Another study, conducted in California, US, used the surveys of 354 MSM clients of public testing services to identify the most important aspects of HIV testing [18]. Of the participants who preferred public clinic testing as their chosen type of service, $45 \%$ mentioned familiarity and professionalism of staff when asked about their reasoning [18].

Two studies conducted in Australia used sentinel surveillance, surveys and focus groups to evaluate PRONTO!, a peer-led, rapid testing, community shop-front model of HIV and STI testing [64,72]. Analysis of evaluation surveys from 416 MSM found that most participants were comfortable waiting for their results with peer-test facilitators and that they found these facilitators to be competent, professional and capable of providing any information and referrals required. The majority $(65.3 \%)$ of participants indicated that they preferred testing with peer-test facilitators compared to sexual health doctors or nurses. The focus groups revealed that participants thought that one of the main benefits of the peer-testing model was that it allowed for meaningful discussion of sexual health and broader issues relevant to the population. They felt they could ask questions they would normally not ask other health professionals. Participants also valued the relationships built with peer staff and noted that the testing experience was enhanced by having testers they could relate to. Although confidentiality concerns were raised and some unease about potentially knowing the staff, this was outweighed by the professionalism displayed by testers $[64,72]$.

\subsubsection{Results and Support}

Six studies identified the importance of receiving positive results in person or over the phone rather than by text or another format $[15,19,20,31,37,78]$. A study conducted in the UK that focused on home-sampling kits highlighted that MSM found a 'no news is good news' approach caused anxiety and uncertainty, and participants preferred to be notified with a negative result [15]. It also found that they preferred to be offered various options for results delivery (i.e., phone, text, email, post) [15].

Eight studies identified the importance of education and counselling with HIV /STI testing $[18,36,48,59,71,76-78]$, with seven studies identifying the lack of these services in self-testing being a barrier to testing $[14,20,24,50,60,81,82]$. A study that used data from the 2011/2012 Sex Now Survey (a serial online survey of MSM in Canada) to explore perceived benefits and drawbacks of Internet-based testing found that the biggest concerns regarding self-testing were the inability to see a health professional or to discuss results, and receiving results online [75]. Another study conducted six focus-group discussions with 47 MSM in England to examine their ideal HIVST service [20]. Participants had positive views of self-testing; however, they feared having no support if there was a positive result. A 24/7 telephone helpline was the most preferred method of support alongside HIVST [20].

\subsection{Societal Attributes}

Stigma Associated with HIV/STI Testing

Ten studies identified stigma of HIV/STI testing to be a deterrent to testing (Table 3). A study conducted in the UK utilised twelve focus groups with 55 multi-professional, patient and provider 'expert' participants to explore barriers and facilitators of self-testing amongst MSM [49]. It was discussed that stigma associated with testing was a barrier to accessing sexual health services, and many MSM would not attend GUM clinics for testing for this reason. It was noted that self-testing would reduce this barrier and potentially reach MSM who were not testing due to this [49]. Another study conducted in-depth, semi-structured interviews with 16 MSM in Australia and explored barriers to accessing HIV and STI 
testing [37]. Stigma was highlighted to be a significant barrier within this community, including internalised stigma and fears of being publicly outed, with one participant highlighting the "culture of avoidance" amongst this population. Education about sexual minorities was suggested to be an important step in facing this issue [37]. Four of these studies [32,83], noted concerns about being seen at the clinic and its associated stigma. A study conducted eight focus-group discussions with 61 MSM in the UK, to explore their views and experiences of accessing sexual health services [32]. Many participants discussed being self-conscious attending a service and felt as though they were drawing attention to themselves and why they were there, with one participant describing it as a "walk of shame" [32]. Five studies suggested possible solutions to minimise the stigma surrounding HIV/STI testing. These included the implementation of peer-led testing, home self-testing and an opt-out testing system $[14,30,36,62,76]$.

Table 3. Identified attributes of STI testing services—societal attributes.

\begin{tabular}{cc}
\hline Attribute & Attribute Examples \\
\hline Risk of Being Stigmatised & Fear of being seen/community finding out $(-)[32,83]$ \\
\hline Fears of family/peers finding out $(-)[15,83]$ \\
\hline Fears of job/insurer discrimination $(-)[19]$ \\
\hline Stigma of STI testing $(-)[19,28,32,34,37,41,48,49,71,83]$ \\
\hline Fear of judgement from tester/negative treatment $(-)$ \\
{$[38,66]$} \\
\hline Preventing Stigma & Peer-led testing $(+)[64,72]$ \\
\hline & Home-self testing $(+)[14,30]$ \\
\hline (+) study reported this as a preferred attribute; $(-)$ study reported this as a non-preferred attribute.
\end{tabular}

\section{Discussion}

This scoping review identified attributes of HIV/STI testing services that influence MSM to access regular testing. Synthesising the extant literature provides an overview of the most important attributes, which are crucial in optimising current testing options for this population. We found that most studies focused on 'service-level' attributes, highlighting the appeal of self-testing, rapid-testing, free/cheap services and skilled testers with positive attitudes. The importance of convenience, offering various testing options and providing a positive testing experience were key themes throughout this review. These data provide valuable insights to assist in adapting current service models or creating new services focused on improving access to testing for MSM.

Access to self-testing was an important attribute across various studies; this was primarily due to convenience. This was reflected by the increased uptake of testing found in three RCTs $[17,21,54]$. Although concerns were raised about the accuracy of self-testing and the difficulty of use, it remained one of the most popular options across studies. Services should evaluate how to best utilise self-testing to encourage regular testing amongst MSM. Making self-testing readily available and improving promotion would likely be beneficial and should be explored.

For service-level attributes, a range of preferences were identified such as the method of testing and results delivery. It was noted that services should ideally offer a variety of options to appeal to subpopulations of MSM. Cost was a key component, with cheaper or free options having a significant impact on the services MSM would access and how regularly they get tested $[17,18,42,50,55,56,71]$. Identifying the type of testing most suitable to individuals by taking these preferences into consideration early on would likely greatly impact MSM returning for regular testing. Additionally, appropriate education was needed for HIV /STI testing, with some preferences based on incomplete information. For example, perceived greater accuracy of blood testing drove a preference for this method 
of testing $[20,28,34]$. Overall, the data suggest that in combination with appropriate pretesting counselling, a service that offers both self-testing and standard testing (at least one of which is free or cheap) and the ability to choose how results are delivered would be popular amongst MSM. Additionally, education surrounding the options available for testing should be provided on a larger scale, both within appointments and across other platforms such as social media.

The testing experience was an important influence on MSM and their HIV /STI testing habits. This included confidentiality and privacy, tester characteristics and stigma, which were particularly important considerations amongst this population. Confidentiality and privacy were recurring themes throughout study findings and greatly influenced preferences. It was identified as one of the key reasons self-testing was preferred, and was a barrier for accessing in-clinic testing. A previous negative testing experience was a significant barrier to testing in the future [28,31-35]. The barrier that stigma imposes on HIV / STI testing can only be partially addressed by optimising testing services as stigma is a community-wide issue that will require interventions directed towards the entire community. However, assessing the benefits and feasibility of implementing strategies such as peer-led testing, home self-testing, and an opt-out testing system is an important consideration for all testing services $[14,30,64,72,84]$.

Distinct patterns of preferences for subpopulations of MSM were identified across several studies. Self-testing appeared to be more attractive to young MSM and first-time testers, while in-clinic testing was preferred by those who perceived themselves as high risk (i.e., symptomatic or exposed to a partner with known infection) [15]. Furthermore, African American MSM generally preferred to be tested by health professionals and to receive information about testing and their test results from clinicians [28,81,82].

The strength of this scoping review is that, to our knowledge, this is the first attempt to synthesise the data of the attributes of HIV/STI testing preferred by MSM living in high-income countries. Limitations of this study include that the majority of studies were conducted within the US, the UK and Australia. Therefore, data from other high-income countries, particularly Asian and European countries, were limited. We only included studies published in English and thus potentially missed relevant studies from high-income countries. We also did not include grey literature which may contain other relevant data. Additionally, most of the studies analysed focused on comparing specific attributes; for example, preferences of a select number of testing methods, rather than looking at how people traded off between numerous attributes and their relative importance. We only found one study using a discrete-choice experiment that attempted this [69].

Further research is required into the preferences of subpopulations of MSM. It was noted that the few studies that addressed subpopulations such as African American MSM might have skewed the results of this scoping review, and therefore in the future, research focusing solely on these subpopulations is required. Additionally, further research should be conducted on testing preferences for MSM with different risk profiles, or symptomatic and asymptomatic MSM, to identify the most effective approach to testing. This scoping review also only included high-income countries, and it would be beneficial to also look at data from low- and middle- income countries.

\section{Conclusions}

This scoping review found that MSM have a diverse range of preferences for HIV /STI testing services, and it is important to address 'individual', 'service' and 'societal' attributes in order to make HIV/STI testing more accessible and encourage regular screening. This includes enhancing the convenience of testing and providing a service that men feel comfortable and safe accessing. Self-testing is a valuable tool to increase access to testing amongst this population; however, offering variety within a service is equally essential to enhance reach. Services should accommodate the preferences of diverse sub-populations within the MSM community, and further research is required to facilitate this. 
Supplementary Materials: The following supporting information can be downloaded at: https: / / www.mdpi.com/article/10.3390/ijerph19053002/s1: Table S1: Search Strategy: PUBMED; Table S2: Search Strategy: EMBASE; Table S3: Search Strategy: PsychINFO; Table S4: Search Strategy: CINAHL; Table S5: PRISMA Checklist; Table S6: Summary of Included Study Characteristics and PREFS* Scores.

Author Contributions: J.J.O. designed the project and J.G. conducted the search. V.K. and J.G. independently screened and extracted data from the studies. C.K.F. and E.P.F.C. contributed to provide advice throughout the project. V.K. wrote the manuscript and all authors critically revised the manuscript. All authors have read and agreed to the published version of the manuscript.

Funding: No funding was provided to conduct this systemic review. J.J.O and E.P.F.C. are supported by an Australian National Health and Medical Research Council (NHMRC) Emerging Leadership Investigator Grants (GNT1193955, GNT1172873) outside the submitted work.

Data Availability Statement: All relevant data have been published in the manuscript or in the supplementary material. Further details can be obtained by writing to the corresponding author.

Conflicts of Interest: All authors declare no conflicts of interest.

\section{References}

1. Centers for Disease Control and Prevention. Sexually Transmitted Disease Surveillance 2017; U.S. Department of Health and Human Services: Atlanta, GA, USA, 2018.

2. Cawley, C.; Marcus, U. Review of HIV and Sexually Transmitted Infections among Men Who Have Sex with Men (MSM) in Europe; Publications Office of the European Union: Luxembourg, 2019.

3. Australian Government Department of Health. Fourth National Sexually Transmissible Infections Strategy. Available online: https: //www1.health.gov.au/internet/main/publishing.nsf/Content/ohp-bbvs-1/ / \$File/STI-Fourth-Nat-Strategy-2018-22.pdf (accessed on 25 February 2022).

4. STIGMA. Australian Sexually Transmitted Infection \& HIV Testing Guidelines 2019 for Asymptomatic Men Who Have Sex with Men. Available online: https://stipu.nsw.gov.au/wp-content/uploads/STIGMA_Guidelines2019_Final-1.pdf (accessed on 25 February 2022).

5. $\quad$ DiNenno, E.A.; Prejean, J.; Irwin, K.; Delaney, K.P.; Bowles, K.; Martin, T.; Tailor, A.; Dumitru, G.; Mullins, M.M.; Hutchinson, A.B. Recommendations for HIV screening of gay, bisexual, and other men who have sex with men-United States, 2017. MMWR Morb. Mortal. Wkly. Rep. 2017, 66, 830. [CrossRef] [PubMed]

6. Zhang, C.; Li, X.; Brecht, M.-L.; Koniak-Griffin, D. Can self-testing increase HIV testing among men who have sex with men: A systematic review and meta-analysis. PLoS ONE 2017, 12, e0188890.

7. Yilu, Q.; Larry, H.; Andrew BABBITT, J.S.W.; Fengying, L.; Harsha THIRUMURTHY, W.T.; Joseph, D.T. Experiences using and organizing HIV self-testing: A global qualitative systematic review. AIDS 2018, 32, 371.

8. Golden, S.D.; Earp, J.A. Social ecological approaches to individuals and their contexts: Twenty years of health education \& behavior health promotion interventions. Health Educ. Behav. 2012, 39, 364-372. [CrossRef] [PubMed]

9. Llewellyn, C.; Pollard, A.; Smith, H.; Fisher, M. Are home sampling kits for sexually transmitted infections acceptable among men who have sex with men? J. Health Serv. Res. Policy 2009, 14, 35-43. [CrossRef]

10. Wayal, S.; Llewellyn, C.; Smith, H.; Fisher, M. Home sampling kits for sexually transmitted infections: Preferences and concerns of men who have sex with men. Cult. Health Sex. 2011, 13, 343-353. [CrossRef]

11. Balan, I.; Frasca, T.; Ibitoye, M.; Dolezal, C.; Carballo-Dieguez, A. Fingerprick Versus Oral Swab: Acceptability of Blood-Based Testing Increases If Other STIs Can Be Detected. AIDS Behav. 2017, 21, 501-504. [CrossRef]

12. Katz, D.A.; Golden, M.R.; Hughes, J.P.; Farquhar, C.; Stekler, J.D. HIV Self-testing increases HIV testing frequency in high-risk men who have sex with men: A randomized controlled trial. J. Acquir. Immune Defic. Syndr. 2018, 78, 505-512. [CrossRef]

13. Skolnik, H.S.; Phillips, K.A.; Binson, D.; Dilley, J.W. Deciding where and how to be tested for HIV: What matters most? J. Acquir. Immune Defic. Syndr. (1999) 2001, 27, 292-300. [CrossRef]

14. Spielberg, F.; Branson, B.M.; Goldbaum, G.M.; Lockhart, D.; Kurth, A.; Celum, C.L.; Rossini, A.; Critchlow, C.W.; Wood, R.W. Overcoming barriers to HIV testing: Preferences for new strategies among clients of a needle exchange, a sexually transmitted disease clinic, and sex venues for men who have sex with men. J. Acquir. Immune Defic. Syndr. 2003, 32, 318-327. [CrossRef]

15. Witzel, T.C.; Rodger, A.J.; Burns, F.M.; Rhodes, T.; Weatherburn, P. HIV Self-Testing among Men Who Have Sex with Men (MSM) in the UK: A Qualitative Study of Barriers and Facilitators, Intervention Preferences and Perceived Impacts. PLoS ONE 2016, 11, e0162713. [CrossRef] [PubMed]

16. Jamil, M.S.; Prestage, G.; Fairley, C.K.; Grulich, A.E.; Smith, K.S.; Chen, M.; Holt, M.; McNulty, A.M.; Bavinton, B.R.; Conway, D.P. Effect of availability of HIV self-testing on HIV testing frequency in gay and bisexual men at high risk of infection (FORTH): A waiting-list randomised controlled trial. Lancet HIV 2017, 4, e241-e250. [CrossRef] 
17. Zhang, Y.; Guy, R.J.; Smith, K.S.; Jamil, M.S.; Prestage, G.; Applegate, T.L.; Conway, D.P.; Holt, M.; Keen, P.; Bavinton, B.; et al. Sustaining success: A qualitative study of gay and bisexual men's experiences and perceptions of HIV self-testing in a randomized controlled trial. BMC Public Health 2021, 21, 2048. [CrossRef] [PubMed]

18. Witzel, T.C.; Bourne, A.; Burns, F.M.; Rodger, A.J.; McCabe, L.; Gabriel, M.M.; Gafos, M.; Ward, D.; Collaco-Moraes, Y.; Dunn, D.T.; et al. HIV self-testing intervention experiences and kit usability: Results from a qualitative study among men who have sex with men in the SELPHI (Self-Testing Public Health Intervention) randomized controlled trial in England and Wales. HIV Med. 2020, 21, 189-197. [CrossRef]

19. Raffe, S.; Pollard, A.; Vera, J.H.; Soni, S.; Peralta, C.; Rodriguez, L.; Dean, G.; Llewellyn, C.D. HIV self-tests for men who have sex with men, accessed via a digital vending machine: A qualitative study of acceptability. Int. J. STD AIDS 2020, 31, 420-425. [CrossRef]

20. Balán, I.C.; Rios, J.L.; Lentz, C.; Arumugam, S.; Dolezal, C.; Kutner, B.; Rael, C.T.; Ying, A.W.; Macar, O.U.; Sia, S.K. Acceptability and Use of a Dual HIV/Syphilis Rapid Test and Accompanying Smartphone App to Facilitate Self- and Partner-Testing Among Cisgender Men and Transgender Women Who Have Sex with Men. AIDS Behav. 2022, 26, 35-46. [CrossRef]

21. Biello, K.B.; Horvitz, C.; Mullin, S.; Mayer, K.H.; Scott, H.; Coleman, K.; Dormitzer, J.; Norelli, J.; Hightow-Weidman, L.; Sullivan, P.; et al. HIV self-testing and STI self-collection via mobile apps: Experiences from two pilot randomized controlled trials of young men who have sex with men. Mhealth 2021, 7, 26. [CrossRef]

22. Iribarren, S.; Lentz, C.; Sheinfil, A.Z.; Giguere, R.; Lopez-Rios, J.; Dolezal, C.; Frasca, T.; Balán, I.C.; Tagliaferri Rael, C.; Brown, W., 3rd; et al. Using an HIV Self-test Kit to Test a Partner: Attitudes and Preferences Among High-Risk Populations. AIDS Behav. 2020, 24, 3232-3243. [CrossRef]

23. Hubach, R.D.; O’Neil, A.M.; Stowe, M.; Hamrick, J.; Giano, Z.; Currin, J.M. Preferred Methods of HIV and Sexually Transmissible Infection Screening Delivery Among a Rural Sample of Men Who Have Sex with Men. AIDS Patient Care STDS 2020, 34, 470-476. [CrossRef]

24. Eaton, E.F.; Austin, E.L.; Dodson, C.K.; Heudebert, J.P.; Jackson, D.; Muzny, C.A. Do young black men who have sex with men in the deep south prefer traditional over alternative STI testing? PLoS ONE 2018, 13, e0209666. [CrossRef]

25. Medline, A.; Daniels, J.; Marlin, R.; Young, S.; Wilson, G.; Huang, E.; Klausner, J.D. HIV Testing Preferences Among MSM Members of an LGBT Community Organization in Los Angeles. J. Assoc. Nurses AIDS Care JANAC 2017, 28, 363-371. [CrossRef] [PubMed]

26. Cushman, T.A.; Graves, S.K.; Little, S.J. Attitudes and preferences regarding the use of rapid self-testing for sexually transmitted infections and HIV in San Diego area men who have sex with men. Open Forum Infect. Dis. 2019, 6. [CrossRef]

27. Datta, J.; Reid, D.; Hughes, G.; Mercer, C.H.; Wayal, S.; Weatherburn, P. Places and people: The perceptions of men who have sex with men concerning STI testing: A qualitative study. Sex. Transm. Infect. 2018, 94, 46-50. [CrossRef] [PubMed]

28. Feinstein, B.A.; Dellucci, T.V.; Graham, S.; Parsons, J.T.; Mustanski, B. Sexually transmitted infections among young men who have sex with men: Experiences with diagnosis, treatment, and reinfection. Sex. Res. Soc. Policy A J. NSRC 2018, 15, 172-182. [CrossRef]

29. Frye, V.; Wilton, L.; Hirshfield, S.; Chiasson, M.A.; Lucy, D.; Usher, D.; McCrossin, J.; Greene, E.; Koblin, B. Preferences for HIV test characteristics among young, Black Men Who Have Sex with Men (MSM) and transgender women: Implications for consistent HIV testing. PLoS ONE 2018, 13, e0192936. [CrossRef] [PubMed]

30. Scheim, A.I.; Travers, R. Barriers and facilitators to HIV and sexually transmitted infections testing for gay, bisexual, and other transgender men who have sex with men. AIDS Care Psychol. Soc.-Med. Asp. AIDS/HIV 2017, 29, 990-995. [CrossRef]

31. Heijman, T.; Zuure, F.; Stolte, I.; Davidovich, U. Motives and barriers to safer sex and regular STI testing among MSM soon after HIV diagnosis. BMC Infect. Dis. 2017, 17, 194. [CrossRef]

32. Hoyos, J.; Koutentakis, K.; Maté, T.; Pulido, J.; Sordo, L.; Guerras, J.M.; Belza, M.J. High risk men who have sex with men in Spain are reporting low intentions of actively seeking HIV testing: Results from a cross-sectional study. BMC Public Health 2020, 20, 398. [CrossRef]

33. Balan, I.C.; Lopez-Rios, J.; Nayak, S.; Lentz, C.; Arumugam, S.; Kutner, B.; Dolezal, C.; Macar, O.U.; Pabari, T.; Wang Ying, A.; et al. SMARTtest: A Smartphone App to Facilitate HIV and Syphilis Self- and Partner-Testing, Interpretation of Results, and Linkage to Care. AIDS Behav. 2019, 24, 1560-1573. [CrossRef]

34. Barnard, S.; Free, C.; Bakolis, I.; Turner, K.M.E.; Looker, K.J.; Baraitser, P. Comparing the characteristics of users of an online service for STI self-sampling with clinic service users: A cross-sectional analysis. Sex. Transm. Infect. 2018, 94, 377-383. [CrossRef]

35. Chen, M.Y.; Bilardi, J.E.; Lee, D.; Cummings, R.; Bush, M.; Fairley, C.K. Australian men who have sex with men prefer rapid oral HIV testing over conventional blood testing for HIV. Int. J. STD AIDS 2010, 21, 428-430. [CrossRef] [PubMed]

36. Lea, T.; Anning, M.; Wagner, S.; Owen, L.; Howes, F.; Holt, M. Barriers to accessing hiv and sexual health services among gay men in Tasmania, Australia. J. Gay Lesbian Soc. Serv. Q. J. Community Clin. Pract. 2019, 31, 153-165. [CrossRef]

37. Tan, R.K.J.; Kaur, N.; Kumar, P.A.; Tay, E.; Leong, A.; Chen, M.I.; Wong, C.S. Clinics as spaces of costly disclosure: HIV/STI testing and anticipated stigma among gay, bisexual and queer men. Cult. Health Sex. 2020, 22, 307-320. [CrossRef] [PubMed]

38. Maxwell, S. General Practitioners' views and experiences on the barriers and facilitators that men who have sex with men have when accessing primary care for HIV testing and sexual health screening. Prim. Health Care Res. Dev. 2018, 19, 205-209. [CrossRef] [PubMed] 
39. Cohall, A.; Dini, S.; Nye, A.; Dye, B.; Neu, N.; Hyden, C. HIV testing preferences among young men of color who have sex with men. Am. J. Public Health 2010, 100, 1961-1966. [CrossRef]

40. Clark, H.A.; Oraka, E.; DiNenno, E.A.; Wesolowski, L.G.; Chavez, P.R.; Pitasi, M.A.; Delaney, K.P. Men Who Have Sex with Men (MSM) Who Have Not Previously Tested for HIV: Results from the MSM Testing Initiative, United States (2012-2015). AIDS Behav. 2019, 23, 359-365. [CrossRef]

41. Dodge, B.; Van Der Pol, B.; Rosenberger, J.G.; Reece, M.; Roth, A.M.; Herbenick, D.; Fortenberry, J.D. Field collection of rectal samples for sexually transmitted infection diagnostics among men who have sex with men. Int. J. STD AIDS 2010, 21, 260-264. [CrossRef]

42. Mustanski, B.; Moskowitz, D.A.; Moran, K.O.; Rendina, H.J.; Newcomb, M.E.; Macapagal, K. Factors Associated with HIV Testing in Teenage Men Who Have Sex with Men. Pediatrics 2020, 145. [CrossRef]

43. den Daas, C.; Geerken, M.B.R.; Bal, M.; de Wit, J.; Spijker, R.; Op de Coul, E.L.M. Reducing health disparities: Key factors for successful implementation of social network testing with HIV self-tests among men who have sex with men with a non-western migration background in the Netherlands. AIDS Care Psychol. Socio-Med. Asp. AIDS/HIV 2020, 32, 50-56. [CrossRef]

44. Flowers, P.; Riddell, J.; Park, C.; Ahmed, B.; Young, I.; Frankis, J.; Davis, M.; Gilbert, M.; Estcourt, C.; Wallace, L.; et al. Preparedness for use of the rapid result HIV self-test by gay men and other men who have sex with men (MSM): A mixed methods exploratory study among MSM and those involved in HIV prevention and care. HIV Med. 2017, 18, 245-255. [CrossRef]

45. Knight, R.E.; Chabot, C.; Carson, A.; Thomson, K.; Haag, D.; Gilbert, M.; Shoveller, J. Qualitative analysis of the experiences of gay, bisexual and other men who have sex with men who use GetCheckedOnline.com: A comprehensive internet-based diagnostic service for HIV and other STIs. Sex. Transm. Infect. 2019, 95, 145-150. [CrossRef] [PubMed]

46. Lee, D.; Fairley, C.; Cummings, R.; Bush, M.; Read, T.; Chen, M. Men who have sex with men prefer rapid testing for syphilis and may test more frequently using it. Sex. Transm. Dis. 2010, 37, 557-558. [CrossRef] [PubMed]

47. Witzel, T.C.; Melendez-Torres, G.J.; Hickson, F.; Weatherburn, P. HIV testing history and preferences for future tests among gay men, bisexual men and other MSM in England: Results from a cross-sectional study. BMJ Open 2016, 6, e011372. [CrossRef] [PubMed]

48. Wray, T.B.; Chan, P.A.; Simpanen, E.; Operario, D. A pilot, randomized controlled trial of HIV self-testing and real-time post-test counseling/referral on screening and preventative care among men who have sex with men. AIDS Patient Care STDs 2018, 32, 360-367. [CrossRef] [PubMed]

49. Ong, J.J.; De Abreu Lourenco, R.; Street, D.; Smith, K.; Jamil, M.S.; Terris-Prestholt, F.; Fairley, C.K.; McNulty, A.; Hynes, A.; Johnson, K.; et al. The Preferred Qualities of Human Immunodeficiency Virus Testing and Self-Testing Among Men Who Have Sex with Men: A Discrete Choice Experiment. Value Health 2020, 23, 870-879. [CrossRef]

50. John, S.A.; Starks, T.J.; Rendina, H.J.; Parsons, J.T.; Grov, C. High willingness to use novel HIV and bacterial sexually transmitted infection partner notification, testing, and treatment strategies among gay and bisexual men. Sex. Transm. Infect. 2020, 96, 173-176. [CrossRef]

51. Johnson, M.C.; Chung, R.; Leung, S.J.; Edelstein, Z.; Yuan, Y.; Flavin, S.M. Combating Stigma Through HIV Self-Testing: New York State's HIV Home Test Giveaway Program for Sexual Minorities. J. Public Health Manag. Pract. 2022, 28, 174-183. [CrossRef]

52. Leenen, J.; Hoebe, C.; Ackens, R.P.; Posthouwer, D.; van Loo, I.H.M.; Wolffs, P.F.G.; Dukers-Muijrers, N. Pilot implementation of a home-care programme with chlamydia, gonorrhoea, hepatitis B, and syphilis self-sampling in HIV-positive men who have sex with men. BMC Infect. Dis. 2020, 20, 925. [CrossRef]

53. Maté, T.; Hoyos, J.; Guerras, J.M.; Agustí, C.; Chanos, S.; Kuske, M.; Fuertes, R.; Stefanescu, R.; Pulido, J.; Sordo, L.; et al. Potential of HIV Self-Sampling to Increase Testing Frequency Among Gay, Bisexual, and Other Men Who Have Sex with Men, and the Role of Online Result Communication: Online Cross-Sectional Study. J. Med. Internet Res. 2020, 22, e21268. [CrossRef]

54. Nash, S.G.; Maffeo, M.; Likatavicius, G.; Cosmaro, L.; Rudaitis, K.; Lapsinov, A.; Enayat, Q.; Delpech, V.; Kall, M. Acceptability and usability of HIV self-tests in two European countries: Findings from surveys of clients at non-governmental organisations in Lithuania and Italy. BMC Infect. Dis. 2021, 21, 844. [CrossRef]

55. Sullivan, S.P.; Sullivan, P.S.; Stephenson, R. Acceptability and Feasibility of a Telehealth Intervention for STI Testing Among Male Couples. AIDS Behav. 2021, 25, 4029-4043. [CrossRef] [PubMed]

56. Hoyos, J.; Maté, T.; Guerras, J.M.; Donat, M.; Agustí, C.; Kuske, M.; Fuertes, R.; Chanos, S.; Pichon, F.; Sordo, L.; et al. Preference towards HIV Self-Testing above Other Testing Options in a Sample of Men Who Have Sex with Men from Five European Countries. Int. J. Environ. Res. Public Health 2021, 18, 4804. [CrossRef] [PubMed]

57. Conway, D.P.; Guy, R.; Davies, S.C.; Couldwell, D.L.; McNulty, A.; Smith, D.E.; Keen, P.; Cunningham, P.; Holt, M. Rapid HIV Testing Is Highly Acceptable and Preferred among High-Risk Gay and Bisexual Men after Implementation in Sydney Sexual Health Clinics. PLoS ONE 2015, 10, e0123814. [CrossRef]

58. Ryan, K.E.; Pedrana, A.; Leitinger, D.; Wilkinson, A.L.; Locke, P.; Hellard, M.E.; Stoove, M. Trial and error: Evaluating and refining a community model of HIV testing in Australia. BMC Health Serv. Res. 2017, 17, 692. [CrossRef] [PubMed]

59. Strömdahl, S.; Liljeros, F.; Thorson, A.E.; Persson, K.I.; Forsberg, B.C. HIV testing and prevention among foreign-born Men Who have Sex with Men: An online survey from Sweden. BMC Public Health 2017, 17, 1-9. [CrossRef] [PubMed]

60. Miners, A.; Nadarzynski, T.; Witzel, C.; Phillips, A.N.; Cambiano, V.; Rodger, A.J.; Llewellyn, C.D. Preferences for HIV testing services among men who have sex with men in the UK: A discrete choice experiment. PLoS Med. 2019, 16, e1002779. [CrossRef] 
61. Holt, M.; Bernard, D.; Race, K. Gay men's perceptions of sexually transmissible infections and their experiences of diagnosis: 'Part of the way of life' to feeling 'dirty and ashamed'. Sexual Health 2010, 7, 411-416. [CrossRef]

62. Hoyos, J.; Belza, M.J.; Fernandez-Balbuena, S.; Rosales-Statkus, M.E.; Pulido, J.; de la Fuente, L. Preferred HIV testing services and programme characteristics among clients of a rapid HIV testing programme. BMC Public Health 2013, 13, 791. [CrossRef]

63. Hottes, T.S.; Farrell, J.; Bondyra, M.; Haag, D.; Shoveller, J.; Gilbert, M.; Hottes, T.S.; Farrell, J.; Bondyra, M.; Haag, D.; et al. Internet-based HIV and sexually transmitted infection testing in British Columbia, Canada: Opinions and expectations of prospective clients. J. Med. Internet Res. 2012, 14, e41. [CrossRef]

64. Leitinger, D.; Ryan, K.E.; Brown, G.; Pedrana, A.; Wilkinson, A.L.; Ryan, C.; Hellard, M.; Stoove, M. Acceptability and HIV prevention benefits of a peer-based model of rapid point of care HIV testing for Australian gay, bisexual and other men who have sex with men. AIDS Behav. 2018, 22, 178-189. [CrossRef]

65. D'Angelo, A.B.; Morrison, C.A.; Lopez-Rios, J.; MacCrate, C.J.; Pantalone, D.W.; Stief, M.; Grov, C. Experiences Receiving HIV-Positive Results by Phone: Acceptability and Implications for Clinical and Behavioral Research. AIDS Behav. 2021, 25, 709-720. [CrossRef] [PubMed]

66. Martin, L.; Knight, V.; Read, P.J.; McNulty, A. Clients' preferred methods of obtaining sexually transmissable infection or HIV results from Sydney Sexual Health Centre. Sex. Health 2013, 10, 91-92. [CrossRef] [PubMed]

67. Tobin, K.; Edwards, C.; Flath, N.; Lee, A.; Tormohlen, K.; Gaydos, C.A. Acceptability and feasibility of a Peer Mentor program to train young Black men who have sex with men to promote HIV and STI home-testing to their social network members. AIDS Care Psychol. Socio-Med. Asp. AIDS/HIV 2018, 30, 896-902. [CrossRef] [PubMed]

68. Contesse, M.G.; Fredericksen, R.J.; Wohlfeiler, D.; Hecht, J.; Kachur, R.; Strona, F.V.; Katz, D.A. Acceptability of Using Geosocial Networking Applications for HIV/Sexually Transmitted Disease Partner Notification and Sexual Health Services. Sex. Transm. Dis. 2020, 47, 41-47. [CrossRef] [PubMed]

69. Pant Pai, N.; Smallwood, M.; Desjardins, L.; Goyette, A.; Birkas, K.G.; Vassal, A.F.; Joseph, L.; Thomas, R. An Unsupervised Smart App-Optimized HIV Self-Testing Program in Montreal, Canada: Cross-Sectional Study. J. Med. Internet Res. 2018, 20 , e10258. [CrossRef] [PubMed]

70. Wohlfeiler, D.; Hecht, J.; Volk, J.; Fisher Raymond, H.; Kennedy, T.; McFarland, W. How can we improve online HIV and STD prevention for men who have sex with men? Perspectives of hook-up website owners, website users, and HIV/STD directors. AIDS Behav. 2013, 17, 3024-3033. [CrossRef]

71. Roy, A.; King, C.; Gilson, R.; Richardson, D.; Burns, F.; Rodger, A.; Clark, L.; Miners, A.; Pollard, A.; Desai, S.; et al. Healthcare provider and service user perspectives on STI risk reduction interventions for young people and MSM in the UK. Sex. Transm. Infect. 2020, 96, 26-32. [CrossRef]

72. Gilbert, M.; Hottes, T.S.; Kerr, T.; Taylor, D.; Fairley, C.K.; Lester, R.; Wong, T.; Trussler, T.; Marchand, R.; Shoveller, J.; et al. Factors associated with intention to use internet-based testing for sexually transmitted infections among men who have sex with men. J. Med. Internet Res. 2013, 15, e254. [CrossRef]

73. Frank, T.D.; Carter, A.; Jahagirdar, D.; Biehl, M.H.; Douwes-Schultz, D.; Larson, S.L.; Arora, M.; Dwyer-Lindgren, L.; Steuben, K.M.; Abbastabar, H. Global, regional, and national incidence, prevalence, and mortality of HIV, 1980-2017, and forecasts to 2030, for 195 countries and territories: A systematic analysis for the Global Burden of Diseases, Injuries, and Risk Factors Study 2017. Lancet HIV 2019, 6, e831-e859. [CrossRef]

74. UNAIDS. UNAIDS Data 2020. Available online: https://www.unaids.org/en/resources/documents/2020/unaids-data (accessed on 25 February 2022).

75. Mathews, A.; Farley, S.; Conserve, D.F.; Knight, K.; Le'Marus, A.; Blumberg, M.; Rennie, S.; Tucker, J. “Meet people where they are": A qualitative study of community barriers and facilitators to HIV testing and HIV self-testing among African Americans in urban and rural areas in North Carolina. BMC Public Health 2020, 20, 494. [CrossRef]

76. Pollard, A.; Llewellyn, C.; Smith, H.; Richardson, D.; Fisher, M. Opt-out testing for HIV: Perspectives from a high prevalence community in south-east England, UK. Int. J. STD AIDS 2013, 24, 307-312. [CrossRef] [PubMed]

77. Lechuga, J.; Owczarzak, J.T.; Petroll, A.E. Marketing the HIV test to MSM: Ethnic differences in preferred venues and sources. Health Promot. Pract. 2013, 14, 433-440. [CrossRef] [PubMed]

78. Saadatmand, H.J.; Bernstein, K.T.; McCright, J.; Gallaread, A.; Philip, S.S.; Lippman, S.A. Young men's preferences for sexually transmitted disease and reproductive health services in San Francisco, California. Sex. Transm. Dis. 2012, 39, 421-423. [CrossRef] [PubMed]

79. Chow, E.P.; Grulich, A.E.; Fairley, C.K. Epidemiology and prevention of sexually transmitted infections in men who have sex with men at risk of HIV. Lancet HIV 2019, 6, e396-e405. [CrossRef]

80. UNAIDS. Fact Sheet-Latest Global and Regional Statistics on the Status of the AIDS Epidemic. Available online: https://www. unaids.org/sites/default/files/media_asset/UNAIDS_FactSheet_en.pdf (accessed on 15 November 2021).

81. Martin, L.; Knight, V.; Ryder, N.; Lu, H.; Read, P.J.; McNulty, A. Client feedback and satisfaction with an express sexually transmissible infection screening service at an inner-city sexual health center. Sex. Transm. Dis. 2013, 40, 70-74. [CrossRef]

82. Gilbert, M.; Thomson, K.; Salway, T.; Haag, D.; Grennan, T.; Fairley, C.K.; Buchner, C.; Krajden, M.; Kendall, P.; Shoveller, J.; et al. Differences in experiences of barriers to STI testing between clients of the internet-based diagnostic testing service GetCheckedOnline.com and an STI clinic in Vancouver, Canada. Sex. Transm. Infect. 2019, 95, 151-156. [CrossRef] 
83. Gu, J.; Lau, J.T.F.; Tsui, H. Psychological factors in association with uptake of voluntary counselling and testing for HIV among men who have sex with men in Hong Kong. Public Health 2011, 125, 275-282. [CrossRef]

84. Baytop, C.; Royal, S.; Hubbard McCree, D.; Simmons, R.; Tregerman, R.; Robinson, C.; Johnson, W.D.; McLaughlin, M.; Price, C. Comparison of strategies to increase HIV testing among African-American gay, bisexual, and other men who have sex with men in Washington, DC. AIDS Care Psychol. Socio-Med. Asp. AIDS/HIV 2014, 26, 608-612. [CrossRef] 